\title{
Giant Mixed Lipoma/Liposarcoma of the Thigh: Diagnostic Approaches and Surgical Management
}

Bertozzi E ${ }^{1}$ Migliano $E^{1, *}$, Cristiani $\mathbf{R}^{1}$, Mazzaracchio $\mathbf{D}^{1}$, Visca $\mathbf{P}^{3}$, Biagini $\mathbf{R}^{2}$, and Bucher $\mathbf{S}^{1}$

${ }^{1}$ Plastic Surgery Unit, S.Maria e S. Gallicano Institute - IFO, Rome, Italy

${ }^{2}$ Orthopedic Surgery Unit, Regina Elena Institute - IFO, Rome, Italy

${ }^{3}$ Pathological Anatomy Unit, Regina Elena Institute - IFO, Rome, Italy

\begin{abstract}
A 58 years old male with a subcutaneous neoformation, localized at the medial surface of the left thigh, of about $30 \mathrm{~cm}$ in diameter, and which has grown larger, particularly during the last year is described. Clinical signs inclined towards a diagnosis of a soft-tissue neoplasm such as giant lipoma. Gigantic lipoma of the thigh are rare. These lesions are of interest because of their risk of recurrency following surgical excision, as well as their potential risk of malignant transformation. We present a case of giant, deforming lipoma with $5 \%$ of the mass resulted compatible with dedifferentiated grade III liposarcoma of the thigh, with emphasis on the diagnostic difficulties encountered, and the surgical management of the case.
\end{abstract}

Keywords: Giant lipoma; Mixed liposarcoma; Open surgery; Adipose tumors

\section{Introduction}

The most common and frequent subcutaneous tumour is welldifferentiated encapsulated lipoma composed of mature adypocites (mature lipoid cells). This neoplasm, with a prevalence rate of 2,1/1000 $[1,2]$ is a slow growing, with a somewhat soft consistency. The ethiology of lipoma is still unknown. Lipoma can be casual, or they may be hereditary. Theoretically metabolic/endocrine or genetic disorders may be involved [3]. Traumatic events have been implicated in the development of lipomas [4]. Lipomas frequently are small, weighing just a few grams, and they are usually less than $2 \mathrm{~cm}$ in diameter. They are usually movable but sometimes fixed by overlying adjacent tissues, which they may displace. However, these lesions can weigh over $200 \mathrm{~g}$ and measure over $10 \mathrm{~cm}$ in diameter [5].

\section{Study Aim}

This study describes our case management of a giant liposarcoma of the thigh in July 2005.

\section{Methods \\ Surgical treatment}

The patient was operated under general anaesthesia in a dorsalrecumbent position.

The mass, as well as the overlying skin, and the biopsy tracts were removed. To reach the mass, the blood vessels were moved aside, the fascia was incised circumferentially, the mass was identified and isolated, the sciatic nerve was moved aside, and the mass removed intact, together with the gracilis muscle. The surgical resection consisted of a $35 \times 25 \times 27$ $\mathrm{cm}$ soft tissue specimen. We left a macroscopically clean margin. Two lymph nodes were identified and removed from the fascia. To cover the femoral vasculo-nervous complex, the nearby muscles were converged and a large distal, pedicled, fascio-cutaneous flap was harvested from the thigh. The donor site was covered with a dermatome-obtained skin graft. A drainage tube was placed, in aspiration, under the flap. Intra-operative antibiotics were administered and continued postoperatively. Heparin, 4000 i.u. a day was administered. At the end of the operation, the haemoglobin value decreased $1.8 \mathrm{~g} / \mathrm{dl}$ to $10.8 \mathrm{~g} / \mathrm{dl}$ with a haematocrit value of $32 . \%$. On the fifth post-operative day an infection of the apex of the flap (which was otherwise perfectly vital) arised. Microbiological culture study found a Pseudomonas Aeruginosa. Using an appropriate antibiotic therapy, in association with frequent dressing changes, the infection was successfully treated. Only a slight wound distal dehiscence of the flap healed by second intention.

\section{Case report}

In July 2005 the following case came to our attention. A 58 year old male who reported, about 3 years earlier, a subcutaneous asymptomatic swelling localized at the upper one third interior aspect of the left thigh. The subcutaneous neoformation demonstrated a fast growth during the last year.

On physical examination, we found a 30 by $20 \mathrm{~cm}$ sphere shaped lump, covered by normal looking skin. The lump was firm and elastic and not painful, even to palpation. No functional problems were reported by the patient. (Figure $1 \mathrm{a}$ and $1 \mathrm{~b}$ ).

Magnetic resonance (MR) of the left thigh showed a voluminous, multi-lobed mass $(27 \times 20 \times 22 \mathrm{~cm})$, with distinct and regular margins, non-infiltrating, but clearly dislocating the adjacent muscle layers (Figure 2). The largest portion of the mass demonstrated internal structure noticeably dis-homogeneous. The mass was vascularized. Part
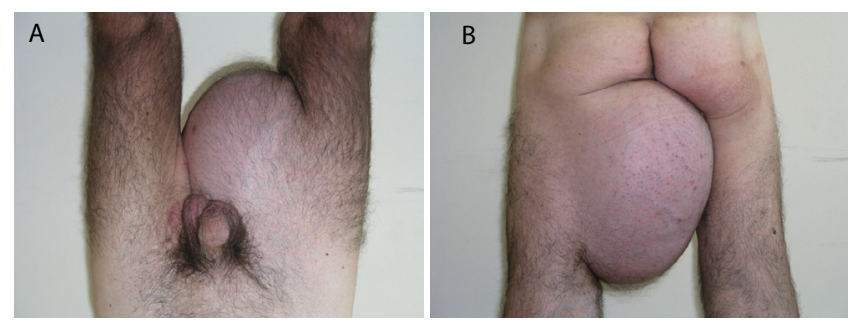

Figure 1a and b: Giant lipoma-liposarcoma of the left thigh in a 58 y.o caucasian male: preoperative view.

${ }^{*}$ Corresponding author: Migliano E, Plastic Surgery Unit, S.Maria e S.Gallicano Institute - IFO, Rome , Italy, Tel: +39 06.52666010; E-mail: miglianoemi@gmail.com

Received December 27, 2013; Accepted October 20, 2014; Published October 28, 2014

Citation: Bertozzi E, Migliano E, Cristiani R, Mazzaracchio D, Visca P, et al. (2014) Giant Mixed Lipoma/Liposarcoma of the Thigh: Diagnostic Approaches and Surgical Management. Surgery Curr Res 4: 206. doi:10.4172/2161-1076.1000206

Copyright: (c) 2014 Bertozzi E, et al. This is an open-access article distributed under the terms of the Creative Commons Attribution License, which permits unrestricted use, distribution, and reproduction in any medium, provided the original author and source are credited. 
Citation: Bertozzi E, Migliano E, Cristiani R, Mazzaracchio D, Visca P, et al. (2014) Giant Mixed Lipoma/Liposarcoma of the Thigh: Diagnostic Approaches and Surgical Management. Surgery Curr Res 4: 206. doi:10.4172/2161-1076.1000206

Page 2 of 3

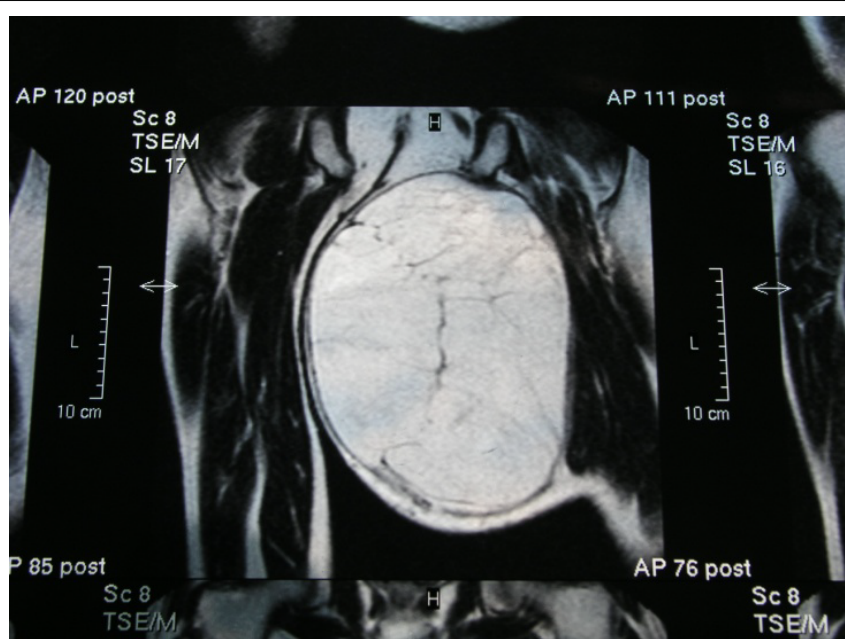

Figure 2: Preoperative MRI study.

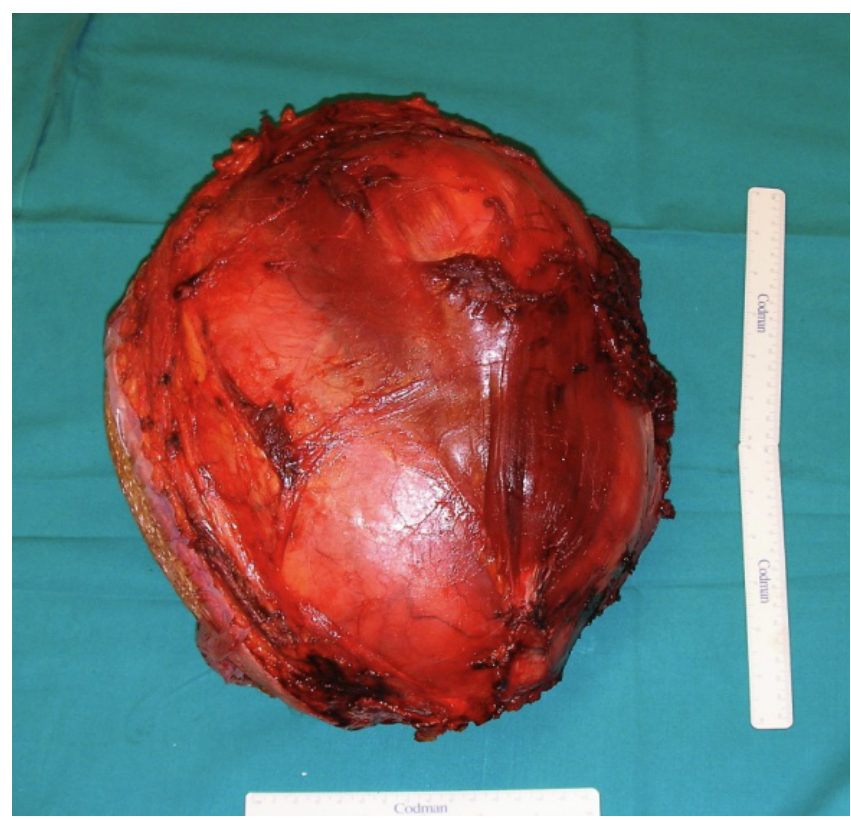

Figure 3: Intraoperative view: the excised specimen together with the gracilis muscle. $8 \mathrm{~kg}$ weight.

of the neurovascular complex was also dislocated laterally and forward. These results suggested a diagnosis of liposarcoma.

However, a preliminary biopsy, performed in a random area of the mass, resulted as lipoma. Subsequently, multiple MRI guided biopsies were performed which resulted as "compatible with well-differentiated liposarcoma (atypical lipoma)". Further testing such as Chest CT scan and abdominal sonogram excluded distant metastases. On the advice of Oncology and Radiotherapy specialists, a wide surgical excision to permit a complete histological examination of the neoplasm and the study of its biological characteristics was performed by our team, together with an orthopaedic team.

\section{Results}

\section{Histologic findings}

The definitive histologic examination evidenced "dedifferentiated grade III liposarcoma", according to the FNCLCC system. The margins were clear and the two lymph nodes showed reactive hyperplasia.

The specimen weighed $8 \mathrm{~kg}$ and only $5 \%$ of the mass was found to be liposarcoma (Figure 3).

The adipocytes showed focal nuclear atypia and hyperchromasia in the presence of stromal cells, multinucleated, especially in fibrous septa, numerous lipoblasts mono and miltinucleated. Immunohistochemical studies showed positive expression for vimentin, S-100, CD30, CD45, desmin, myogenin, smooth muscle actin. Atypical lipomatous tumor subtype liposarcoma well-differentiated adipocyte (lipoma like) (Figure $4)$.

\section{Patient management}

Post- operative total body CT scan was negative.

The patient was treated with a cycle of external radiotherapy, following surgical excision. At 96 months follow-up after surgery no local or distant metastases were found (thigh MRI plus TB CT scan). The patient reports a good quality of life and satisfaction with the outcome (no residual discomfort, no neurologic defect or recurrency or adenopathy), (Figure 5a and 5b).

\section{Discussion}

According to Sanchez et al, in order for a lipoma to be called "giant", the lesion must be at least $10 \mathrm{~cm}$ in one dimension or weigh a minimum of 1000 gr. [5]. One of the largest cutaneous lipomas,

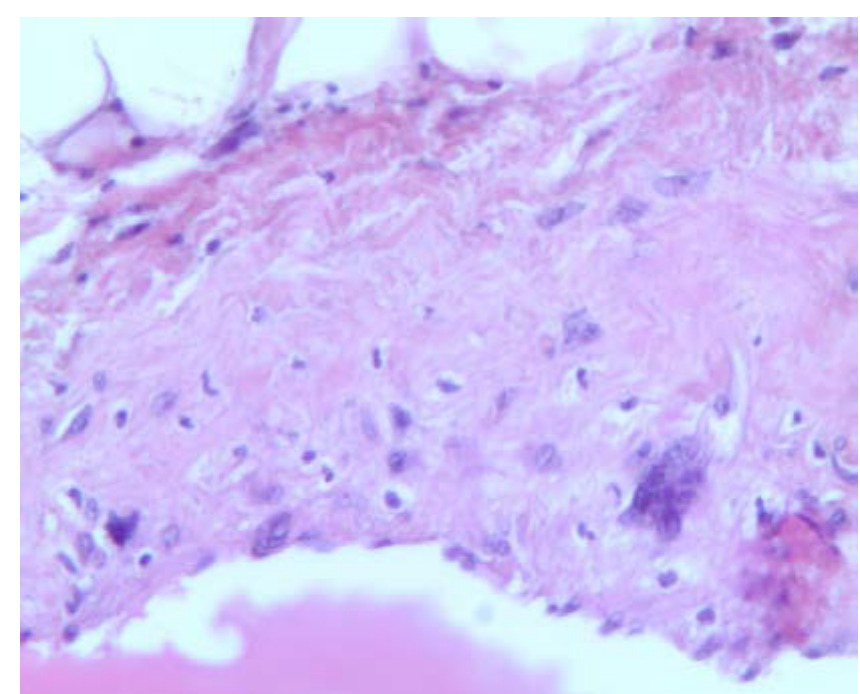

Figure 4: Atypical lipomatous tumor subtype liposarcoma well-differentiated adipocyte (lipoma like).

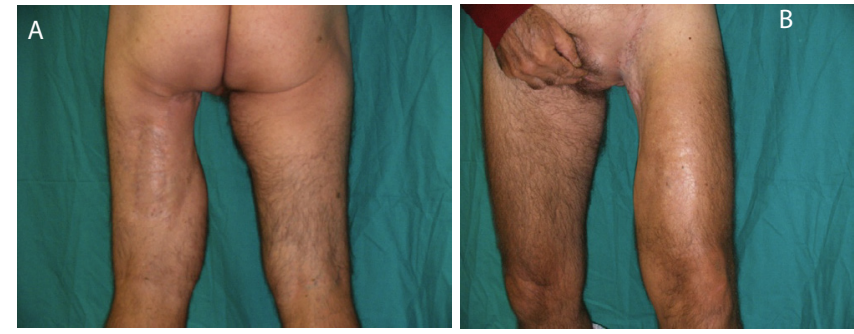

Figure 5a and 5b: Six months postoperative view, after radiotherapy. 
Citation: Bertozzi E, Migliano E, Cristiani R, Mazzaracchio D, Visca P, et al. (2014) Giant Mixed Lipoma/Liposarcoma of the Thigh: Diagnostic Approaches and Surgical Management. Surgery Curr Res 4: 206. doi:10.4172/2161-1076.1000206

Page 3 of 3

reported by Brandler [6] in 1894 , was $22.7 \mathrm{Kg}$, and located on the left scapular region, in a male, 26 years-old patient. Lipomas can grow in many different tissues or organs [1], and they have been found in the extremities, the gastrointestinal tract, the mediastinum, the heart, the brain, and spinal cord.

The malignant transformation of lipoma to liposarcoma is relatively uncommon. A few reports suggest that large tumours ( $>10 \mathrm{~cm}$ in size) are more at risk of containing sarcoma cells $[2,3]$, expecially in the presence of sudden rapid growth [7]. Liposarcoma is the most common malignant mesenchymal neoplasm in adults, classified in 5 subtypes, including well-differentiated, dedifferentiated, myxoid, pleomorphic and mixed liposarcoma.. There are also reports that the intramuscular location of a lipoma is a risk factor for malignancy [2,3]. The lower extremities are one of the most common sites for liposarcomas $[8,9]$. In this site, when diagnosis of liposarcoma is sure, Campbell et al recommends wide excision or amputation if needed [10]. They have reported a high probability of recurrence (91\%) secondary to conservative initial treatment. Some authors have reported that postoperative adjuvant radioterapy lengthens the median survival rate when surgical excision has not been adequate $[7,8,10]$.

Giant lipoma treatment can be by open surgical excision or by liposuction, but it is very important to choose the most appropriate operative technique, considering the possibility of malignant transformation [12].

Fine needle aspiration biopsy and core biopsy usually do not provide sufficient material to allow the pathologist to differentiate between lipoma and liposarcoma [11]. Incisional biopsy is superior expecially when performed in selected areas using MR imaging $[13,14]$.

In our case, the first incisional biopsy wasn't enough to allow correct diagnosis. We suspected a malignant transformation considering the MR images, the size and fast grow. A second incisional biopsy guided by the MR images, allowed the diagnosis of well differentiated liposarcoma. We then excluded distant metastases using CT scan and abdominal sonogram. We then consulted oncological and radiotherapy specialists who suggested a wide surgical excision with a complete histological examination of the whole neoplasm.

According to the literature we chose open radical surgery to removal the whole, capsulated neoplasm, the overlying skin of the external aspect, and the gracylis muscle at the inner aspect.

Currently, the patient is disease free at 8 years follow-up, without surgery associated morbidity and with an optimal satisfaction of the surgical outcome.

\section{Conclusions}

In our opinion open and wide surgical excision, respecting oncological criteria of radicality, is the mandatory method of giant lipoma treatment. Surgical excision allows a complete removal of the macroscopically visible neoplasm, permitting a complete histological evaluation of the tumour to exclude tissutal malignant transformation. Giant lipomas present an high risk of coexisting internal liposarcoma areas, these areas are very difficult to be identified with preoperative studies.

\section{Competing Interests}

The authors declared that they have no competing interests.

\section{Funding sources} (Italy)

IRCCS San Gallicano - Scientific Research Direction Prof A. Di Carlo - Rome

\section{References}

1. Davis C Jr, Gruhn JG (1967).Giant lipoma of the thigh. Arch Surg 95: 151-156

2. Rydholm A, Berg NO (1983) Size, site and clinical incidence of lipoma. Factors in the differential diagnosis of lipoma and sarcoma. Acta Orthop Scand 54: 929934.

3. Silistreli OK, Durmuş EU, Ulusal BG, Oztan Y, Görgü M (2005) What should be the treatment modality in giant cutaneous lipomas? Review of the literature and report of 4 cases. Br J Plast Surg 58: 394-398.

4. Signorini M, Campiglio GL (1998) Posttraumatic lipomas: where do they really come from? Plast Reconstr Surg 101: 699-705.

5. Sanchez MR, Golomb FM, Moy JA, Potozkin JR. (1993) Giant lipoma: case report and review of the literature. J Am Acad Dermatol 28: 266-268.

6. Brandler TI (1894) Large fibrolipoma. Br Med J 1: 574.

7. Terzioglu A, Tuncali D, Yuksel A, Bingul F, Aslan G (2004) Giant lipomas: a series of 12 consecutive cases and a giant liposarcoma of the thigh. Dermato Surg 30: 463-467.

8. Celik C, Karakousis CP, Moore R, Holyoke ED (1980) Liposarcomas: prognosis and management. J Surg Oncol 14: 245-249.

9. Smith TA, Easley KA, Goldblum JR (1996) Myxoid/round cell liposarcoma of the extremities. A clinicopathologic study of 29 cases with particular attention to extent of round cell liposarcoma. Am J Surg Pathol 20: 171-180.

10. Campbell DA Jr, Eckhauser FE, Oehler JR, O'Leary T, Hart WR (1980) Liposarcoma of the lower extremity. Surgery 88: 453-460.

11. Hunt JA, Thompson JF (1997) Giant infiltrating lipoma of the thigh causing sciatica. Aust N Z J Surg 67: 225-226.

12. Campbell GS, Lawrence TJ, Porter SE, Rezeanu L (2012) Primary dedifferenziated liposarcoma of the axilla arising in a mixed well-differentiated and myxoid liposarcoma. J Radiol Case Report. 6: 9-16.

13. Fletcher CDM, Unni KK, Mertens F (2002) Pathology and genetics of tumors of soft tissue and bone: World Health Organization Classification Tumors. Lyon France: IARC Press: 5

14. Peterson JJ, Kransdorf MJ, Bancroft LW, O'Connor MI (2003) Malignant fatty tumors : clasification clinical course, imaging appearance and treatment. Skeletal Radiol. 32: 493-503. 